\title{
The Influence of the Growth Environment on the Online Loan Consumption Behavior of College Students Takes Three Universities in Dezhou as an Example
}

\author{
HongYan $\mathrm{Ye}^{1, \mathrm{a}}$ \\ ${ }^{1}$ Shandong Huayu Institute of Engineering School of Mechanical Engineering, Texas, Shandong, China \\ 1374469377@qq.com
}

\begin{abstract}
Campus network loan has been controversial, this paper through the questionnaire to understand the Dezhou three universities of college students online loan consumption, analyze the growth environment of family environment, peers, the influence of consumer psychology on college students online loan consumption behavior, put forward reasonable countermeasures, guide college students to set up the correct consumption view.
\end{abstract}

Keywords: College students, campus online loan, online loan consumption, growth environment, correct consumption view

\section{成长环境对大学生网贷消费行为的影响 以德州市三所高校为例}

叶红艳 ${ }^{1, a}$

${ }^{1}$ 山东华宇工学院机械工程学院, 德州, 山东, 中国

a1374469377@qq.com

\section{摘要}

校园网贷一直以来饱受争议, 本文通过问卷调查了解德州市三所高校在校大学生网贷消费的现状, 分析成长环 境中家庭环境、同伴影响、消费心理对大学生网贷消费行为的影响, 针对性提出合理对策, 引导大学生树立正 确的消费观。

关键词: 在校大学生, 校园网贷, 网贷消费,成长环境, 正确消费观

\section{1.前言}

校园网贷一方面能够短时间内缓解大学生的消 费压力而被部分大学生所接受; 另一方面, 因为网贷 平台的 “参差不齐”，使得 “高利贷”、“裸贷”、“套路 贷” 等恶性不良网络借贷事件不断出现, 严重侵害着 当代大学生的身心健康, [1]更直接影响甚至扭曲大学 生的消费观、人生观。因此当务之急就是探究大学生 校园网贷表现并就其成因找到解决对策。

\section{2.德州市大学生网贷消费行为现状}

\section{1 调查方法}

为了对德州市三所高校在校大学生网贷消费的 现状及相关情况进行研究, 总结概括出成长环境对德 州市三所高校大学生网贷消费行为的影响, 引导大学 
生树立正确的消费观，本文采用分层随机抽样问卷、 匿名作答的方式，对德州市高校发放问卷 300 份，回 收有效问卷 296 份，有效回收率 $98.6 \%$ 。

\section{2 调查对象}

本次调查对德州市三所高校中大学一年级至四 年级、17 个学院在校大学生进行抽样调查, 回收的 296 分问卷中，男生 160 人，占比 $54.1 \%$, 女生 136 人, 占比 $45.9 \%$; 从调查对象的年级分布来看, 大一 学生占比 $37.4 \%$, 大二学生占比 $32.6 \%$, 大三学生 占比 $26.6 \%$, 大四学生由于毕业在即, 或考研、或 在外实习、找工作等原因, 参与较少, 占 $3.4 \%$ 。

\section{3 调查内容}

调查内容主要包括两个方面。一方面是德州市三 所大学在校大学生的网贷消费行为的基本情况; 另一 方面是分析成长环境中家庭环境、同伴影响、消费心 理对大学生网贷消费的影响。

\section{4 调查结果}

\subsection{1 德州市大学生网贷消费现状}

在 296 名调查对象中, $73.5 \%$ 的学生选择了 “使 用过校园网贷, 还会继续使用”, 其中 “花呗”、“京东 白条” 这两款网贷平台使用率最高, “没用过, 也不感 兴趣” 的学生仅占 $5.2 \%$, 这说明德州市三所高校中, 大多数学生认可 “网贷消费”。从了解网贷的途径中 发现, $58.3 \%$ 的学生是通过 “网络消息”了解, $21 \%$ 的 学生是经 “同伴推荐” 得知, 深入了解后发现, 使用 网贷消费的学生中受“同伴影响”的占比超过了 $60 \%$, 身边同学在一定程度上推动了网贷消费行为的发生。

调查样本中绝大多数学生网贷的数额在 3000 元 以下， $42 \%$ 的学生明确表示会在校园借贷时对自己的 还款能力进行深思熟虑; 但是, 仍然有 $11 \%$ 的学生表 示, 在进行网贷消费时, 从未考虑自己的还款能力就 进行校园网贷, 这些学生中, 低年级学生占比重较多。 在被问及 “你是否觉得校园网贷靠谱”, 仅有 $20 \%$ 的 学生认为, 校园网贷可靠, $18.6 \%$ 的学生认为大学生 进行校园网贷是有益的。而学生之所以选择网贷消费, 多数认为网贷相较于其他借款方式的好处依次是方 便快捷、贷款金额灵活、还款时间灵活、无需做担保, ${ }^{[2]}$ 最后是利息低或无息, 这样更贴合大学生消费的需 求。

2.4.2 成长环境中家庭环境、同伴影响、消费 心理对大学生网贷消费的影响

2.4.2.1家庭环境
为了解调查样本的家庭情况对其校园网贷行为 是否存在影响, 因此从家长的消费观念、教育情况和 家庭氛围等多方面进行调查, 探究学生校园网贷行为 背后家庭环境的影响。

\begin{tabular}{|c|c|c|}
\hline \multicolumn{3}{|c|}{ 表 1 家长是否引导你要树立正确的消费观念 } \\
\hline 是/否 & 样本量/人数 & 所占比例\% \\
\hline 是 & 237 & 80 \\
\hline 否 & 39 & 13.2 \\
\hline 不清楚 & 20 & 6.8 \\
\hline
\end{tabular}

通过表 1 可见, 调查样本中 237 名学生家长引导 孩子树立正确的消费观念, 占总比近 $80 \%$ 的比例。

\begin{tabular}{|c|c|c|}
\hline \multicolumn{2}{|c|}{ 表 2 你的家庭氛围是偏向民主型还是权威型 } \\
\hline 氛围类型 & 样本量/人数 & 所占比例\% \\
\hline 民主型 & 222 & 75 \\
\hline 权威型 & 49 & 16.6 \\
\hline 不知道 & 25 & 8.4 \\
\hline
\end{tabular}

通过表 2 可知, 调查样本中有 222 名学生认为自 己的家庭氛围是民主型的, 仅有 49 名, 认为家中的 氛围是权威型的学生, 占总比 $16.6 \%$ 。

表 3 如果你正在进行或打算进行校园网贷, 你 会主动告知父母吗?

\begin{tabular}{|c|c|c|}
\hline 会/不会主动 & $\begin{array}{c}\text { 样本量/人 } \\
\text { 数 }\end{array}$ & 所占比例\% \\
\hline 会 & 207 & 70 \\
\hline 不会 & 79 & 26.6 \\
\hline 不知道 & 10 & 3.4 \\
\hline
\end{tabular}

通过表 3 可知, 调查样本中接近 70\%的学生认为 自己如果有网贷的意向,会主动告知父母,仅有 $26.6 \%$ 的学生认为自己不会告知父母。

\subsubsection{2 同伴影响}

\begin{tabular}{|c|c|c|}
\hline \multicolumn{3}{|c|}{ 表 4 你身边有同学进行借贷消费? } \\
\hline 使用频率 & 样本量/人数 & 所占比例\% \\
\hline 较多 & 18 & 6 \\
\hline 有 & 88 & 30 \\
\hline 很少 & 74 & 25 \\
\hline 没有 & 44 & 15 \\
\hline 不了解 & 72 & 24 \\
\hline
\end{tabular}

通过表 4 可知, 调查样本中占总比近 $60 \%$ 同学表 示身边同学进行过借贷消费，只是使用的频率不同。

\begin{tabular}{|c|c|c|}
\hline \multicolumn{3}{|c|}{ 表 $\mathbf{5}$ 你好朋友的消费观念如何? } \\
\hline 消费观念 & 样本量/人数 & 所占比例\% \\
\hline 理性消费 & 179 & 60.4 \\
\hline 非理性消费 & 47 & 16 \\
\hline 不清楚 & 70 & 23.6 \\
\hline
\end{tabular}


通过表 5 可知, 调查样本中占总比 $60.4 \%$ 的学生 认为自己好朋友的消费观念是理性消费观念.

表 6 如果身边同学用网贷买到你心仪的贵重物 品，会促使你也这样做吗？

\begin{tabular}{|c|c|c|}
\hline 会/不会 & 样本量/人数 & 所占比例\% \\
\hline 会 & 30 & 10.1 \\
\hline 不会 & 213 & 72 \\
\hline 不知道 & 53 & 17.9 \\
\hline
\end{tabular}

通过表 6 可知, 调查样本中占总比 $72 \%$ 的学生表 示自己不会因为身边同学借助网贷买到自己心仪的 贵重物品, 从而进行校园网贷。

\subsubsection{3 消费心理}

为了解调查对象的消费心理是否是进行校园网 贷行为的影响因素, 因此, 从校园网贷的动机和消费 心理自评等方面进行调查。

\begin{tabular}{|c|c|c|}
\hline \multicolumn{3}{|c|}{ 表 7 你使用校园网贷的动机是? } \\
\hline & 样本量/ & $\begin{array}{c}\text { 人所占 } \\
\text { 比 } \\
\text { 数 }\end{array}$ \\
例\% \\
\hline 使用校园网贷的动机 & 36 & 12 \\
\hline 高端电子产品 & 35 & 15 \\
\hline 旅游、聚餐、恋爱等 & 45 & 9 \\
\hline 购买股票 & 26 & 7 \\
\hline 自主创业 & 20 & \\
\hline 网络游戏、自播等虚拟花 & 35 & 12 \\
\hline 费 & 35 & 14 \\
\hline 网课、兴趣班等提升课程 & 42 & 16 \\
\hline 购买衣服、化妆品等 & 47 & 11 \\
\hline 其他 & 33 & 4 \\
\hline 无 & 12 & 12 \\
\hline
\end{tabular}

通过表 7 可知, 调查样本中学生进行校园网贷的 动机选择人数最多的依次是购买衣服、化妆品等; 旅 游、聚餐、恋爱等交际娱乐; 网课、兴趣班等提升课 程等, 只有极少数人会因为购买股票、理财产品以及 自主创业而进行校园网贷。

\begin{tabular}{|c|c|c|}
\hline \multicolumn{3}{|c|}{ 表 8 你有哪些消费心理 } \\
\hline 消费心理 & 样本量/人数 & 所占比例\% \\
\hline 享乐消费理念 & 96 & 32.5 \\
\hline 攀比消费理念 & 76 & 25.7 \\
\hline 超前消费理念 & 56 & 19.0 \\
\hline 从众消费理念 & 68 & 22.8 \\
\hline
\end{tabular}

通过表 8 可见, 调查样本中学生的消费心理依次 是享乐消费、攀比消费、从众消费、超前消费, 选择 前两种消费心理的学生人数最多, 超过调查总人数的 一半以上。

\section{3.德州市大学生网贷消费行为产生的动机}

\section{1 主观因素}

\section{1.1 享乐、攀比心理}

目前, 德州市三所高校在校大学生以 “ 00 ” 后为 主, 进入大学校园后, 大学生对一切都感到新奇, 从 手机、电脑到衣服、鞋子, 从包包到化妆品, 学生间 无形中都在攀比。部分学生为了跟同伴使用同样的 “高档物品”, 不考虑自身家庭经济情况而进行购买, 只图享乐、攀比。[3] “受到同伴的刺激”, 这一部分大 学生更容易产生攀比心理, 甚至不惜网络借款购买远 远超过自身经济能力的东西。

\section{1.2 盲从、超前心理}

近年来, 依托 “抖音、快手” 等 AAP, 在网红直 播效应、“双 $11 ” 、 “ 618 ”$ 等优惠购物节的催化下， 部分自控能力差的大学生产生盲从心理, 化妆、旅游、 饮食跟着 “抖音” 走, 喜欢就买、新潮就买, 消费欲 望高于自己的经济能力时, 部分大学生不考虑自身偿 还能力, 盲目的选择各类网贷进行超前消费。所以, 大学生使用校园贷, 更多的是因为日常学习生活之外 的消费太多, 加上不能自我控制, 只能借助校园网贷 填补消费缺口。

\subsection{3 缺乏安全意识}

由于大学生还未正式进入社会, 身心发展不够成 熟, 安全意识也不足, 进行网贷消费行为时, 既不考 虑自己还款能力，也不考虑所借贷款的借贷成本，以 及所借贷款平台的正规程度，更难以识别 “校园贷” 合同中的不合理条款，从而导致了一些资质较差的贷 款平台钻空子，进入不良网贷平台的 “陷阱”。[4]

\section{2 客观因素}

\subsection{1 校园网贷的优势吸引}

校园网贷平台通过 “零利息、无担保、放款快” 等口号吸引大学生的注意。一方面, 手续简单便捷, 校园网贷只需学生提供身份证和家庭信息便可成功 借贷，申请程序简单，审核时间短，隔天就可放贷， 金额可大可小; 另一方面, 内部宣传, 鼓动性强, 校 园网贷抓住大学生消费欲望强烈而社会经验不足的 特点, 以 “低门槛、快速放款” 等为诱导条件, 在学 生遇到资金短缺又差于向长辈求助时, 通过大学生作 
“校园代理”, “近身” 鼓动学生网贷, 让大学生一步 步走入预设的泥潭陷阱。

\section{2.2 相关部门对网贷平台监管的缺失}

由于网贷平台准入审核的不完善，导致一些借贷 平台 “良莠不齐”。为了快速发展校园网贷产品, 争夺 客源, 占据市场份额, 一些借贷平台通常会以降低借 贷利率或者给出各种优惠措施来吸引客户, 客户一旦 出现违约的情况, 放贷公司就会露出 “真面目”。有些 借贷公司为了获取更大的利润, “明码标价” 出售借 款人的个人信息，严重侵犯了个人的隐私权。

\section{2.3 学校教育引导的缺位}

德州市三所高校在大学生消费观方面的教育以 及网贷导致严重后果的教育很少, 而且形式上的理论 灌输不能让大学生对于网贷消费行为产生深切的危 机意识, 也并没有对贷款违约所造成的严重后果, 有 任何法律上的担忧。 ${ }^{[5]}$ 然而, 网贷逾期不仅导致个人 信用损失, 而且由于平台参差不齐, 这使得校园网贷 逾期的大学生很容易受到不法分子的侵害。高校教育 引导的缺位, 并不能真正起到教育大学生树立正确消 费观、预防不良网贷消费的目的, 各种不良网贷消费 问题时有发生。

\section{2.4 家庭错误消费观的纵容}

家庭环境对个人有着长远且深刻的影响, 父母的 消费观会直接影响孩子的消费观。部分家长对 “ 00 ” 后大学生的要求几乎都是尽可能的满足, 也有部分学 生家长错把充足的生活费用和优越的物质生活条件 当作是对孩子的爱, 缺乏对孩子的真正关心关爱, 反 而养成了大学生花光用光、透支消费、超前消费的不 良消费观念和消费行为, ${ }^{[6]}$ 这样当学生日常消费无法 得到满足时, 某些学生就会产生网贷念头。

\section{4.德州市大学生网贷消费行为引导策略}

\section{1 社会倡导适度的消费观，营造健康消费氛 围}

预防德州市大学生不良网贷消费, 当今社会不仅 仅应该管制网贷平台, 还应该在社会的整体消费观的 完善方面下功夫。

首先, 弘扬节俭美德, 倡导节制有度的生活方式, 引导大学生的消费价值观和消费行为; 其次, 倡导精 神消费, 扩大文化服务消费, 培育新的文化消费增长 点, 提升消费结构; 最后, 借助大众媒体, 积极发挥 大众传媒的优势, 传播理性的消费观念、科学的消费 观念, 培育适度的消费观念, 营造健康消费氛围。

\section{2 高校加强教育引导，培养正确消费观念}

德州市三所高校加强对大学生消费观、幸福观等 价值观教育, 不仅能促进大学生全面发展, 实现个体 潜能, 也是实现绿色发展和可持续发展的必要手段。

大学应该以校园文化活动为载体, 充分发挥校园 中各种组织的作用, 开展宣传 “绿色消费、适度消费、 健康消费” 的活动, 打造积极向上的校园文化氛围, 提高大学生的消费质量, 抑制大学生的不良消费行为; ${ }^{[7]}$ 加大对不良校园网贷的打击力度, 建立健全监管处 置机制，提高对不良校园网贷的监督检查，净化校园 环境, 同时不断完善大学生奖助贷体系, 以满足大学 生金融消费的实际需要。

\section{3 家庭节制有度，践行绿色消费理念}

家庭是家庭成员之间相互学习的成长场所, 家庭 供给是当前大学生最主要的经济来源, 大学生的消费 水平和消费行为与其家庭之间有着密不可分的关系。

家长作为家庭中的长辈, 要以身作则, 重视精神 消费，杜绝奢侈浪费的消费行为，营造节制有度的家 庭消费氛围, 引导孩子逐步养成勤检朴素的好习惯和 诚实正直的好品德; 在日常生活中, 家长注重培养大 学生的节佮美德, 反对孩子的享乐性和攀比性消费行 为, 教育他们学会理性消费, 使其养成按需购买的消 费习惯。做到家校联合, 共同培养大学生的理性消费 观。

\section{4 大学生提高自控力, 培养良好消费观}

首先, 树立健康、绿色的消费观，不过度消费， 超前消费, 不盲目攀比和跟风消费, 提高自控力。其 次, 利用课余时间, 勤工助学, 而不是一味向父母索 取或者通过校园网贷进行享受, 与此同时加强自身素 质修养, 不贪慕虚荣, 不被物质横流的社会裹挟。最 后, 提高风险防范意识, 不要轻信他人的甜言蜜语, 在日常生活中, 当代大学生保护好个人信息, 不随意 泄露个人信息, 面对各种借贷产品, 不盲目听信广告, 更不要被虚假的诱人条件所吸引, 理性分析, 提高警 惕意识。

\section{5. 结论}

当代大学生群体正处于身心发展的关键阶段, 引 导大学生树立正确的人生观、世界观、价值观, 成长 为社会发展、国家建设所需的高素质人才, 是高校想 政治教育工作者首要任务。大学生的消费行为是进入 社会、建立人际关系的第一步，正确消费观的形成对 其价值观的建立具有极为重要的意义。当前大学生消 费中存在着方方面面需要改进的问题，网贷消费问题 尤为突出。因此, 社会、高校、家庭、大学生自身四 者共同努力, 规范网贷平台, 净化网络消费环境, 引 
导大学生理性面对网贷消费, 养成正确、健康、绿色 的消费行为, 促进大学生正确消费观的形成。

\section{项目基金}

本文为山东华宇工学院校级课题《成长环 境对德州市大学生网贷消费行为的影响》 (2019RW08) 的阶段性成果之一。

\section{REFERENCES}

[1] Cao Hui, H. ( 2020 ) Operation mechanism, infringement type and classification governance of bad campus network loan. Journal of Shenzhen University (Humanities and Social Sciences Edition), 37:120-128.

[2] Yu Yang, Li Yao,Y.Y,(2020)Research on the cultivation path of college students' financial literacy under the background of campus online loan,Guangxi Quality Supervision Guide,03:44-45.

[3] Li Yan, Cao Shubing,Y.S,(2020)The supervision dilemma and legal countermeasures of campus network loan, Gansu finance, 04:43-48.

[4] Yangdong,D,(2016)Use the legal red line to punish the bad "campus online loan",People's Forum,34:83-85.

[5] Liao Yuping, Shao Lei, Y.L,(2017)The risks and response of campus online loans, Journal of Chongqing Industrial and Commercial University (Social Sciences Edition),34:123-128.

[6] Su Chan Juan, CJ,(2017)Analysis of abnormal consumer psychology and educational guidance for college students under the background of campus online loan,Guangxi Social Sciences, 07:218-220.

[7] Zhou Jian, J,(2019)Research on Social Risk of Chinese College Students under Risk Social Vision,Chinese Youth Studies, 108:106-112. 